Journal of Engineering and Applied Sciences 14 (13): 4356-4361, 2019

ISSN: 1816-949X

(C) Medwell Journals, 2019

\title{
Drop Condensation of Steam in a Vertical Tube at Different Pressures
}

\author{
Ayser Muneer \\ Department of Mechanical Engineering, University of Baghdad, Baghdad, Iraq
}

\begin{abstract}
In the present research experimental data on heat transfer are obtained for the condensation of almost pure steam on vertical tubes (polished is gold plated). The condenser pipe is a $12 \mathrm{~mm}$ outer diameter, $96 \mathrm{~mm}$ condenser length tube. The experiments were carried out at steam pressures of $0.15,0.2,0.25,0.3,0.35,0.4$ and $0.45 \mathrm{bar}$, cooling water temperature difference varied from $17-19^{\circ} \mathrm{C}$ and steam generator is rang 900,1200 and $1500 \mathrm{~W}$. In this research, the high rate of heat transfer on the steam-to-wall temperature variance (difference) for dropwies condensation of steam on the vertical tube are determined experimentally for several pressures range. The experimental results are compared with film condensation results at different pressures, the dropwise condensation showed much higher heat transfer rates and film coefficients rate than corresponding filmwise condensation by 3-4 times. However, the dropwise condensation showed even higher condensation rate than filmwise condensation with the different steam pressures. The drowpwise condensation showed that it gradually, increases in the rate of heat transfer as the steam pressure increased and as the cooling water rate decreased.
\end{abstract}

Key words: Dropwise condensation, different steam pressures, different cooling water temperatures, different steam generator, comparison between dropwise and filmwise condensation, pure steam

\section{INTRODUCTION}

Many researchers have been attracted mechanism of dropwise steam condensation (Fujii, 1991). Various analytical and experimental studies have been dedicated to investigate the phenomenon complexity; its non-equilibrium features, the various modes and condensation kinds (filmwise and dropwise condensation), velocity of steam, the steam mixtureand the regimes of the condensate flow, the condensing surface characteristics, the number of various parameters, the geometrical configurations, etc., (Rose, 1998a, b). Most researcher have not adequately accounted for these factors with the result that most data are not reproducible. Moreover, processes of mechanical, investigated by only a few number of researchers have proceeded slowly. The report by the researchers Dolloff et al. (1969), illustrated mechanism of a dropwise condensation steam raised pressure are presented. The heat transfer coefficient was calculated experimentally for pressures to range between from $0-9.5 \mathrm{~atm}$ at $183.3^{\circ} \mathrm{C}$. Observations indicated that for each sub-cooling temperature there's a steam pressure that has a maximum heat transfer coefficient and the heat transfer coefficient increase with decreasing sub-cooling temperature and lies in the sub-cooling temperature range $10-20^{\circ} \mathrm{F}$. Photographic of the dropwise condensation phenomenon that has been analyzed to reveal that the collective effects of drop cycle time, free area and temperature of surface of steam condensation are the factors this the reason a maximum in the condensation coefficient. A theoretical analyses of values is submitted which is consistent with experimental remarks.

Tanaka (1979), the heat transfer rate was determined much safely for steam condensation of the dropwise on the basis of the conduct of photographs droplets. Some equation that have the ability to describe and expression for the substantial growth rate of a one droplet valid down to the thermodynamic critical volume and the process of coalescence and growth of droplets in dropwise condensation. From the compare between the predicted and experimental Nusselt numbers we are stimulated to estimate the dropwise condensation heat transfer coefficient of water as well as that of ethylene glycol at around 0.2 on the assumption that the firstly, droplet can nucleate almost anywhere on the condensing surface. If the heat transfer coefficient should be singularity.

Shigeo and Hiroaki (1987), studied the heat transfer coefficient were determined experimentally for pressure ranging from atmosphere pressure to $1 \mathrm{kPa}$ at different surfaces (A gold-plated copper block, a silicon steam disk plated with gold, an ultra-finished gold disk and two copper blocks deposited with chromium). The results illustrated the heat transfer coefficient decreased with decreasing pressure. Also, the results showed the dropwise condensation heat transfer coefficient was not 
influenced by an apparent variance when the steam pressure is below a few kilo-Newton per meter square (kilo-Pascal's) in the population growth of submicroscopic drops. In addition to Chung et al. (2008), many experimental studies have been devoted the difference between filmwise and dropwise phenomenon of steam condensation on inclined tube or inclined plat.

All these studies were conducted for the dropwise condensation of the water-ethanol vapor mixtures with small concentration. Chindyakov et al. (2017), the research of the water-ethanol vapor mixtures at different concentrations from $8.4-14 \%$ and study of the dropwise condensation heat transfer coefficient are obtained for the condensation of almost immobile pure steam and water-ethanol vapor mixture on a copper horizontal tubes with a cooled length (three finned tube).

This research is report of an extension of work, presented earlier by Muneer (2017) and aims is the experimental study of the dropwise condensation heat transfer coefficient rate, steam condensation rate and heat transfer rate for dropwise condensation of steam in a different pressures rate, generator steam and cooling flow rate. Either, in order to investigate the comparison between dropwise and filmwise condensation of steam in a vertical tube (Published in Issue 9 and Year 2017). In addition, presents the photographic of dropwise and film condensation of steam at different pressures.

\section{MATERIALS AND METHODS}

Experimental apparatus: A schematic diagram of the test facility is shown in Fig. 1 and 2. The two condenser pipes are fixed in the upper surface of the vessel (chamber). Cooling water flow rate pass through the inside of the tubes. The amount of heat given by steam at the condensation pipe can be determined from the measurement of the inlet and outlet Temperatures $T_{1}, T_{2}$ and mass Flow rate $F_{1}$. The cooling water flow rate is controlled by the Valve $V_{1}$. The heater is fitted in the lower part of the vessel and the steam generates steadily at a rate that is controlled by regulating the power supply (Transformer) via. $\mathrm{T}_{7}$ measure the Temperature steam and the different pressures in the vessel by P. The vessel can be evacuated by the pump of water P. For this purpose water is fed to the pump via. the control Valve $V_{3}$. The Valve $V_{4}$ is used to fill the vessel (chamber) with distilled water and drained it. The experimental modeling can be description divided to test section, steam water generator and cooling water flow system.

Test section: The experimental facility consisted of two pipes $\left(\mathrm{K}_{1}, \mathrm{~K}_{2}\right)$ are mounted in the rubber cover of the

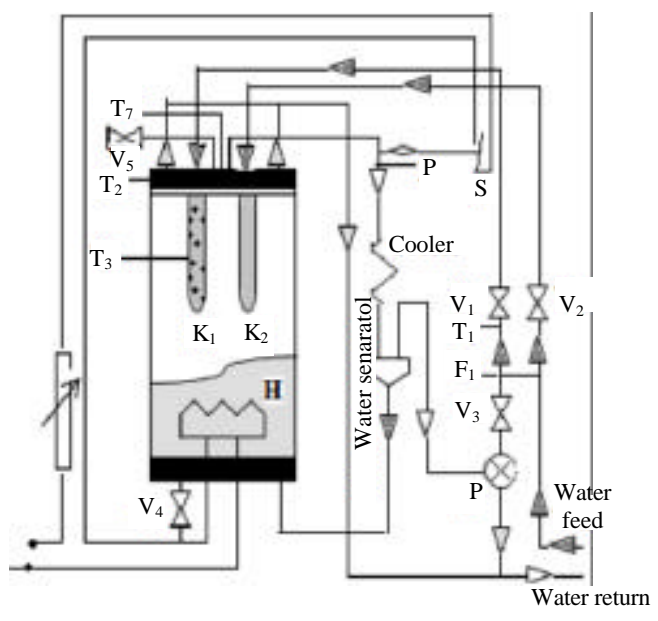

Fig. 1: System schematic diagram

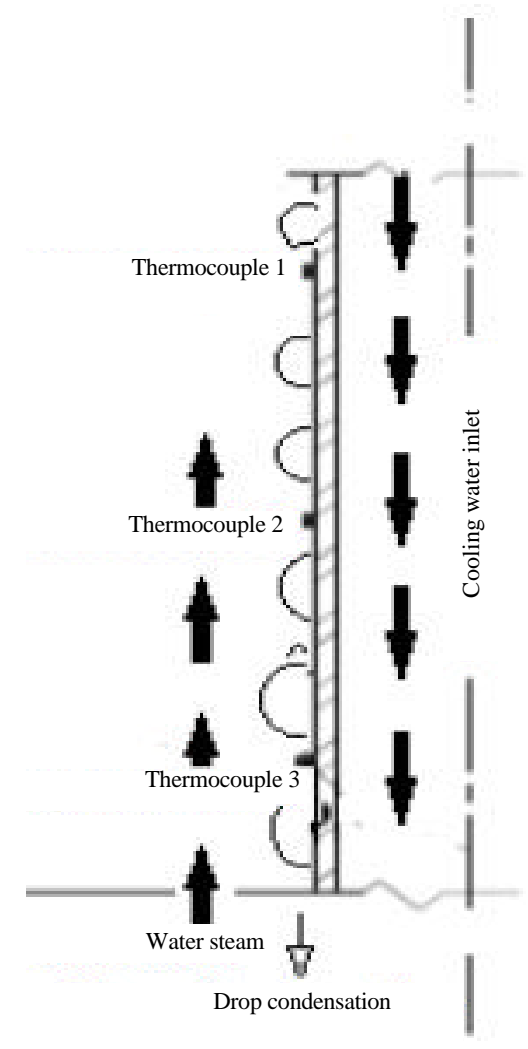

Fig. 2: Condenser tube construction

Pyrex cylinder (the upper part of the chamber). Cooling water flows through them lengthways. On entry, the cooling water is fed through an immersion tube to the lower end of the condenser pipe and then rises up the inner wall. This type of fabricated ensure equal cooling over the entire length of the condenser pipe. The temperature of the surface pipe is measured via. type $\mathrm{K}$ thermocouples. The one pipe is made of copper, so as to 
achieve film condensation (right hand condenser) and the other is polished and gold plated for drop condensation will occur here (left hand condenser). The feed and return temperature of the cooling water flow is measured with a PTC sensor (4) in the lid. The condenser pipe is a $12 \mathrm{~mm}$ outer diameter, $96 \mathrm{~mm}$ condenser length tube and surface area cooled a $36.18 \mathrm{~cm}^{2}$.

Steam generator: The steam generator was a Pyrex cylinder of $750 \mathrm{~mm}$ high, $250 \mathrm{~mm}$ i.d. and $15 \mathrm{~L}$ capacity, of which the upper of two-thirds included water steam and the lower one third was a water chamber. The heater is fixed in the lower part of the chamber (a submerged sheath heater of the type). The output of the heater power is adjustable $(0-3000 \mathrm{~W})$ and the heater power is regulated to ensure desired water temperature using thermostat. To prevent over-accumulation of pressure we install a safety Valve $V_{5}$. The steam temperature in the chamber is measured by two thermocouples (type $\mathrm{K}$ ), of which one was installed in the steam water chamber and the other was placed in the downstream of the test condenser tube.

Adjusting the cooling water flow: The cooling water flow through the condenser pipe is adjusted by Valves $V_{1}$ and the flow rate $(0-200 \mathrm{l} / \mathrm{h})$ can be read off on indicators $F_{1}$. The inlet and outlet cooling water temperature was measured via. thermocouples $\left(T_{1}\right.$ and $\left.T_{2}\right)$, respectively.

\section{Mathematical model}

Condensing tube: The condenser tube of dropwise condensation was made of copper. The surface of tube was painted with a thin layer of gold (this surface enhances water steam condensation for dropwise condensation in a very stable manner). The tube is fitted in the high cover of the chamber. The cooling water flow rate enters the condenser tube from top while the steam from the bottom of the chamber, this assurance high temperature homogeneity of surface and high turbulence for whole range of cooling water rates.

The feed Temperature $\left(\mathrm{T}_{\text {inlet }}\right)$ and return Temperature ( $\mathrm{T}_{\text {outlet }}$ ) of the cooling water flow in the channel, enable the rise temperature in the condenser tube is measured by thermocouples. The heat transfer rate is reliably measured calorimetrically as in Eq. 1 .

$$
\mathrm{Q}=\dot{\mathrm{m}} \mathrm{C}_{\mathrm{P}}\left(\mathrm{T}_{\text {outlet }}-\mathrm{T}_{\text {inlet }}\right)
$$

Where:

${ }_{(\mathrm{m})}=$ The flow rate of the cooling water

$\mathrm{C}_{\mathrm{P}}=$ The specific heat capacity at constant pressure

The heat flux (q) provides an indication of the loading of the condenser surface area Eq. 2:

$$
\mathrm{q}=\frac{\mathrm{Q}}{\mathrm{A}}
$$

The coefficient of heat transfer $\mathrm{h}$ refers to the flow of heat due to the different between steam temperature and surface temperature is determined from the Eq. 3 :

$$
\mathrm{h}=\frac{\mathrm{q}}{\mathrm{A}\left(\mathrm{T}_{\mathrm{s}}-\mathrm{T}_{\text {sur }}\right)}
$$

Test program: The experimental of program was performed in different steam pressures, cooling water temperature and steam generators:

Steam Pressure $\mathrm{P}_{\text {range }}(0.15,0.2,0.25,0.3,0.35,0.4$ and 0.45 bar)

. The heat generated to the evaporation tank $\mathrm{P}_{\text {steam }}$ range $(900,1200$ and $1500 \mathrm{~W})$

. Cooling water Temperature rate $\mathrm{T}_{\text {cool }}$ range (17-19)

Experimental results for different sets of conditions are collected (steam pressure, steam generator and cooling water temperature) and reported to explore the influence of various parameters on the condensation rate, temperature distribution on the tube surface and the thermal characteristics of overall heat transfer coefficient on the condensation process.

\section{RESULTS AND DISCUSSION}

Experimental results for condensation of pure steam: The effect of steam pressure on condensation mass rate is shown clearly on Fig. 3-5. These figures show effect at different cooling water temperature rate and constant steam generator to evaporate the water in the heating vessel. All this figures prove that condensate mass rate increase proportionally versus steam pressure, tube surface temperature and power required water evaporation in the heat vessel. Figure 1 shows the steam condensation rate at $\mathrm{P}_{\text {steam }}=1500 \mathrm{~W}$, the heat transfer on tube surface have more effect when the steam pressure increase with decreasing cooling water Temperature $\left(\mathrm{T}_{\text {cool }}=17-19\right)$, i.e.

In this regard, according to the reduced steam pressure, the dropwise condensation heat transfer coefficient will drop steeply, resulting in the speedy increase in the characteristic droplet volume at which the resistance of thermal becomes equivalent to the thermal conduction resistance through the droplet. Thus, obtaining heat transfer value at pressures as low as possible is very desirable to catch accurately the interfacial thermal resistance and subsequently, the heat transfer coefficient increasing (Tanaka and Hatamiya, 1986). 


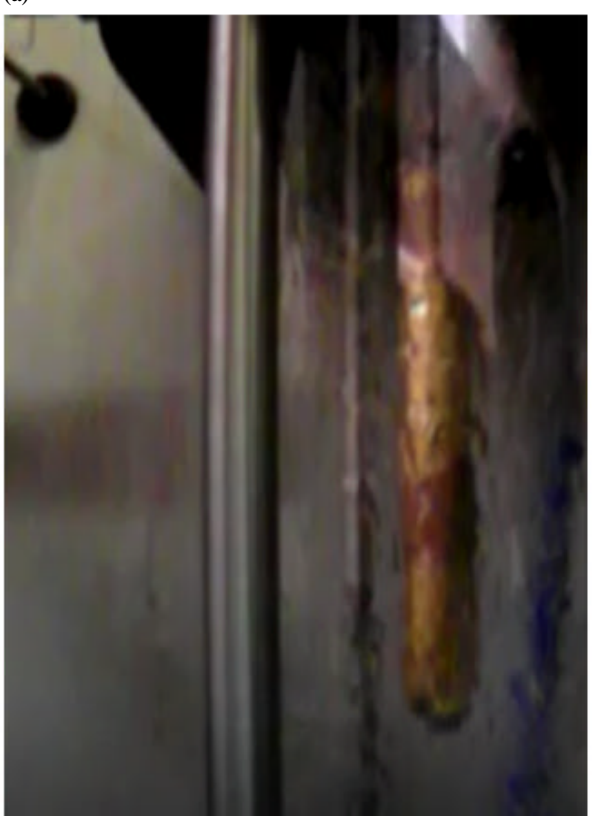

(b)

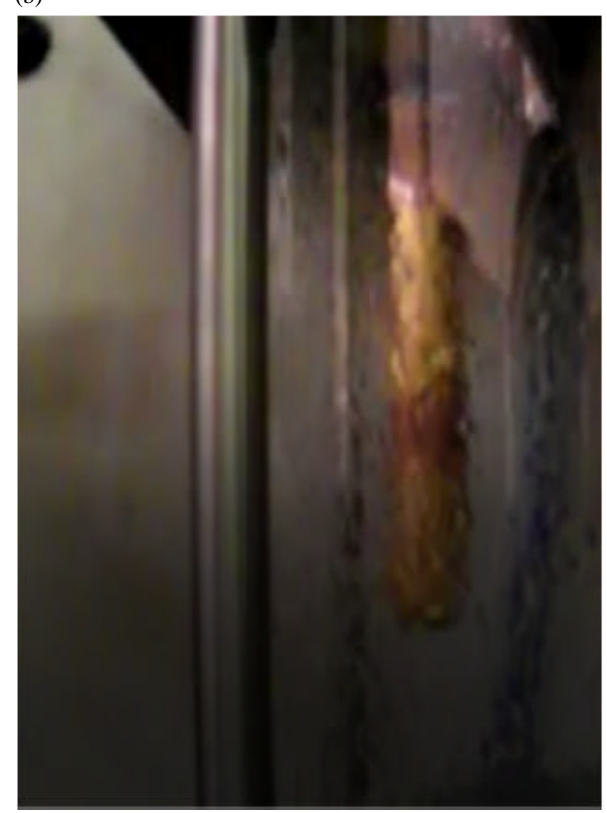

Fig. 3: Comparison of condensation steam of surface at different pressures ( 0.15 and 0.45 bar $)$, heat generator $P_{\text {steam }}=1500$ $\mathrm{W}$ and cooling water Temperature $\mathrm{T}_{\text {cool }}=17^{\circ} \mathrm{C}$ (at the same time)

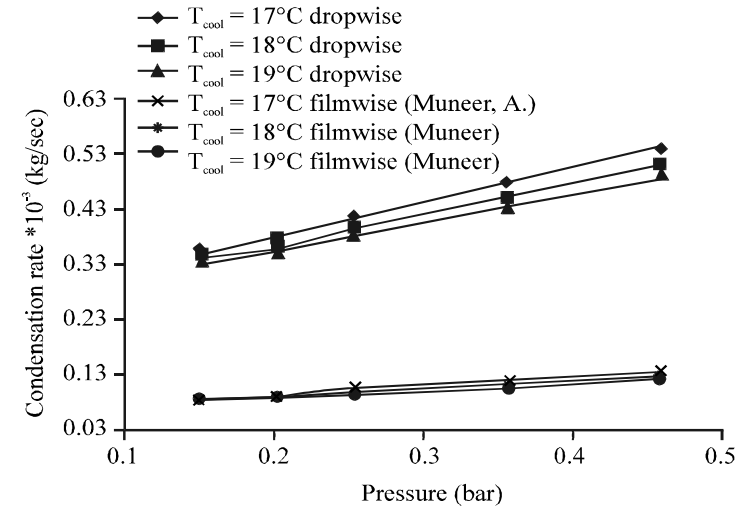

Fig. 4: Variation condensation rate with steam pressure for different cooling water at a constant evaporation Power $\mathrm{P}_{\text {steam }}=1500 \mathrm{~W}$

Figures 5 and 6 shows the similar behavior as Fig. 3 with different steam generator, $P_{\text {steam }}=1200$ and $P_{\text {steam }}=900$ $\mathrm{W}$, respectively. It could be concluded that condensate rate decrease by gradually decreasing steam generator and increasing cooling water temperatures. The greatest value of the steam condensation rate was about $0.6 \dot{\mathrm{m}}$ $10^{-3} \mathrm{~kg} / \mathrm{sec}$, i.e., approximately 3.5 times higher than for film condensation of pure steam on a vertical smooth tube.

The whole experimental results are showed in Fig. 7. Heat transfer rate increases systematically as the steam generator rate increases in both dropwise condensation

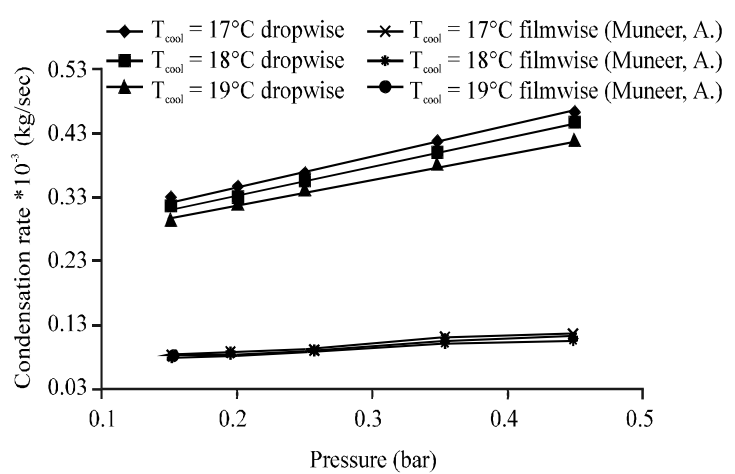

Fig. 5: Variation condensation rate with steam pressure for different cooling water at a constant evaporation Power $\mathrm{P}_{\text {steam }}=1200 \mathrm{~W}$

and filmwise condensation. The film condensation started with slightly lower heat transfer rate than dropwise condensation.

The dropwise condensation, showed 3-4 times higher heat transfer rate than filmwise condensation which may be explained by the fact that the temperature of tube surface was maintained by the heating from the pure steam and cooling from plate cooling water system. In the dropwise condensation test of pure steam the cooling was not sufficient to overcome the heating.

Figure 7 illustrate the influence of steam pressure on the heat transfer rate at constant steam generator power 


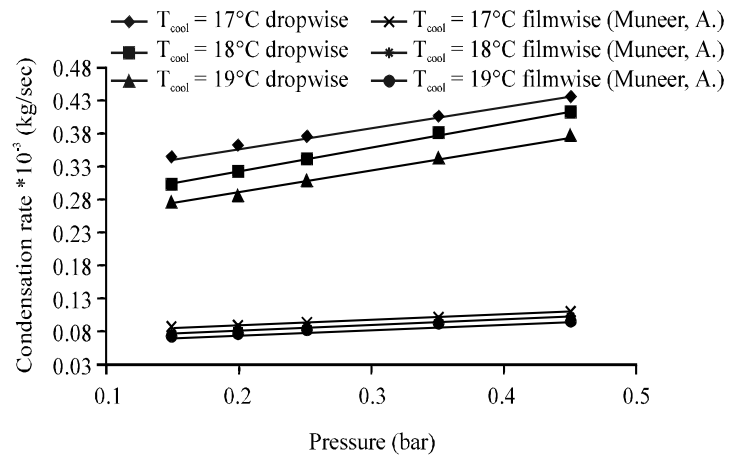

Fig. 6: Variation condensation rate with steam pressure for different cooling water at a constant evaporation Power $\mathrm{P}_{\text {stream }}=900 \mathrm{~W}$

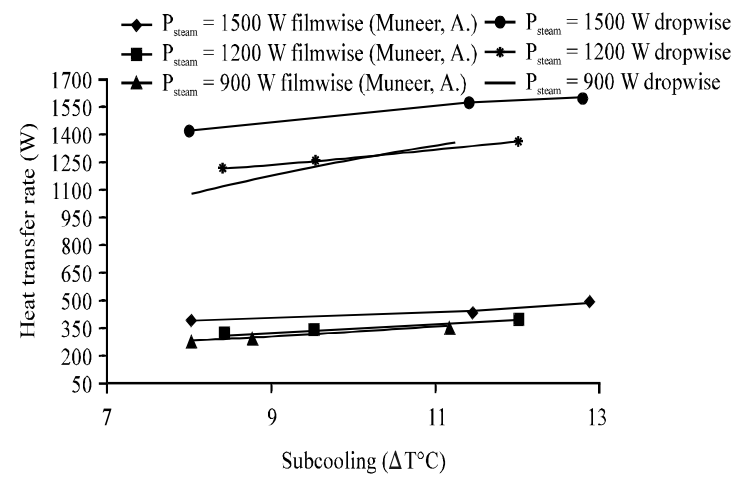

Fig. 7: Variation of heat transfer rate with subcooling at constant Pressure $\mathrm{P}=0.45$ bar

and different cooling water temperature. It is observed that heat transfer rate increases with increasing steam pressure. For example, at a $\mathrm{T}_{\text {cool }}$ of $17^{\circ} \mathrm{C}$ the heat transfer rate $\mathrm{Q}$ is $1390 \mathrm{~W}$ for a pressure of 0.2 bars. At this same $\mathrm{T}_{\text {cool }}$ the heat transfer rate almost 0.7 -fold to $1496 \mathrm{~W}$ as the pressure increases to 0.25 bar. This increase was not caused by an increase in velocity of water steam because the water steam velocity actually decreased as the steam pressure increased.

Figure 8 and 9 show the effect of surface subcooling on the condensate heat transfer coefficient at different steam pressure. The increasing of the pressure led to increase the condensation coefficient and decrease the subcooling. The variation of the dropwise condensation heat transfer coefficient performance with steam temperature resulted from the change of the condensate surface free energy. The decreasing the condensate surface free energy while increasing the steam temperature to result in a large increase in the number of drop nucleation sites (Song et al., 1991) and a decrease in the drop departure diameter (Rose, 1998a, b). However,

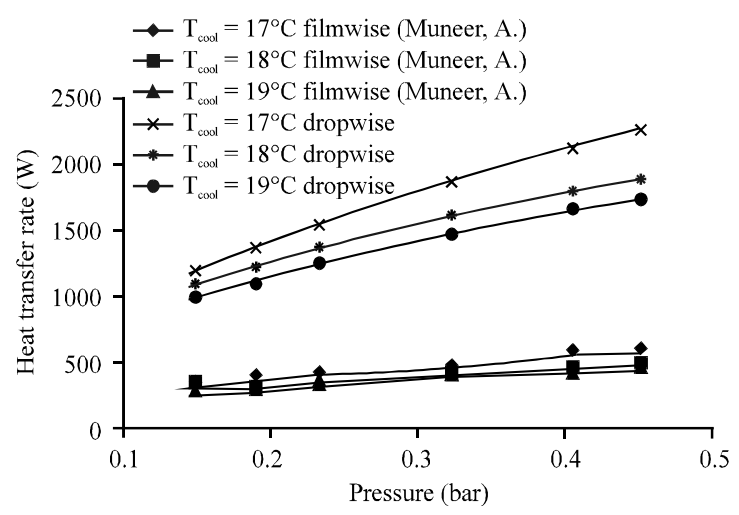

Fig. 8: Variation of heat transfer rate with steam pressure at a constant steam generator $\mathrm{P}_{\text {steam }}=1500 \mathrm{~W}$

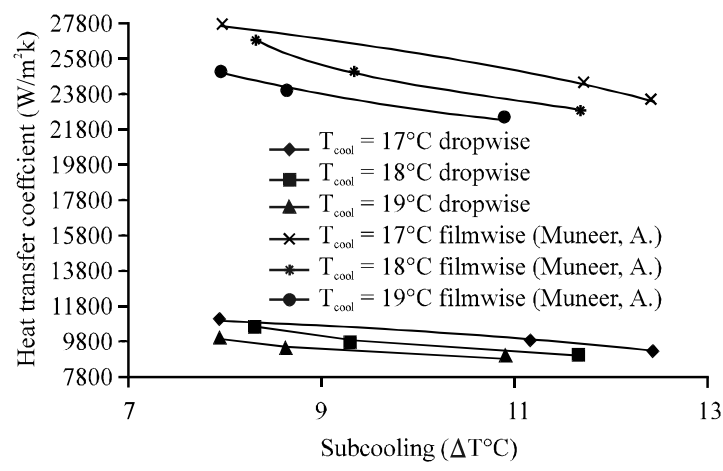

Fig. 9: Variation of heat transfer coefficient with subcoolingat a constant pressure $=0.4 \mathrm{bar}$

increasing the steam temperature may cause the interfacial heat transfer coefficient between the condensate and steam to decrease while the increasing steam pressure flattens the condensing drops. Therefore, the increasing the steam temperature causes the dropwise condensation heat transfer performance to deteriorate (Ma et al., 2001).

\section{CONCLUSION}

The condensation mass rates for dropwise condensation of steam increased with increasing steam pressure

The condensation mass rate for the dropwise condensation is higher than that for filmwise condensation is around 3 times higher

Heat transfer rate measurement's decreases with decreasing steam pressure while the heat transfer rate increases with increasing subcooling temperature

The heat-transfer coefficient for dropwise condensation of steam decreased with increasingsubcooling 


\section{NOMENCLATURE}

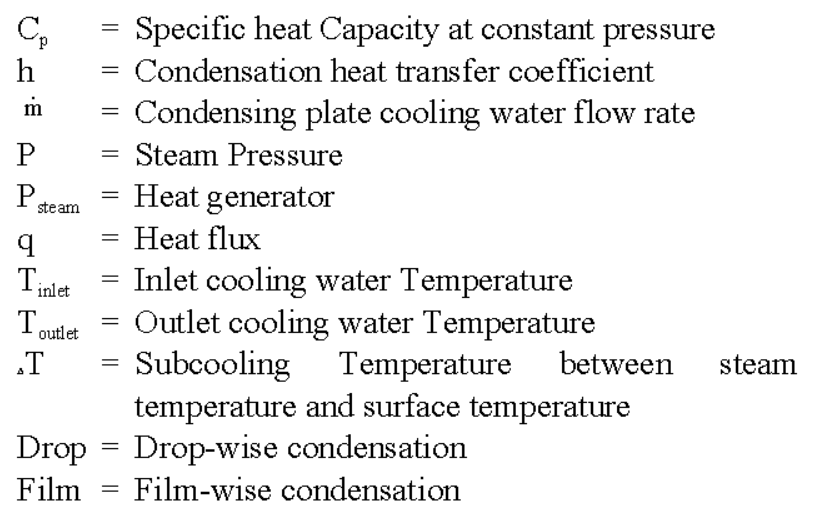

\section{REFERENCES}

Chindyakov, A.A., Y.B. Smirnov and E.V. Mikhailova, 2017. Heat transfer during pseudo-dropwise condensation of water-ethanol vapor mixture on horizontal finned tubes. J. Phys. Conf. Ser., 891: $1-7$.

Chung, B.J., M.C. Kim and M. Ahmadinejad, 2008. Film-wise and drop-wise condensation of steam on short inclined plates. J. Mech. Sci. Technol., 22: 127-133.

Dolloff, J.B., N.H. Metzger and L.H.S. Roblee $\mathrm{Jr}$, 1969. Dropwise condensation of steam at elevated pressures. Chem. Eng. Sci., 24: 571-583.
Fujii, T., 1991. Theory of Laminar Film Condensation. Springer, Berlin, Germany, ISBN:978-1-4612-3152-3, Pages: 213.

Ma, X., B. Tao, J. Chen, D. Xu and J. Lin, 2001. Dropwise condensation heat transfer of steam on a polytethefluoroethylene film. J. Thermal Sci., 10: 247-253.

Muneer, A., 2017. Film condensation on a vertical tube at different pressures. Assoc. Arab Univ. J. Eng. Sci., 24: $241-253$.

Rose, J.W., 1998b. Condensation heat transfer fundamentals. Chem. Eng, Res. Des., 76: 143-152.

Rose, J.W., 1998a. Interphase matter transfer, the condensation coefficient and dropwise condensation. Heat Transfer Conf., 1: 89-104.

Shigeo, H. and T. Hiroaki, 1987. Dropwise condensation of steam at low pressures. Intl. J. Heat Mass Transfer, 30: 497-507.

Song, Y.J., D.C. Zhang and J.F. Lin, 1991. Effect of steam temperature on dropwise condensation heat transfer. J. Chem. Ind. Eng. China, 42: 119-123.

Tanaka, H. and S. Hatamiya, 1986. Drop size distributions and heat transfer in dropwise condensation-condensation coefficient of water at low pressures. Proceedings of the 8th International Conference on Heat Transfer Vol. 4, August 17-22, 1986, San Francisco, California, USA., pp: 1671-1676.

Tanaka, H., 1979. Further developments of dropwise condensation theory. J. Heat Transfer, 101: 603-611. 